\title{
Biomethane Production as an Alternative Bioenergy Source from Codigesters Treating Municipal Sludge and Organic Fraction of Municipal Solid Wastes
}

\author{
M. Evren Ersahin, Cigdem Yangin Gomec, R. Kaan Dereli, Osman Arikan, \\ and Izzet Ozturk \\ Department of Environmental Engineering, Istanbul Technical University, Maslak, 34469 Istanbul, Turkey \\ Correspondence should be addressed to Cigdem Yangin Gomec, yanginci@itu.edu.tr
}

Received 27 July 2010; Revised 5 October 2010; Accepted 30 November 2010

Academic Editor: R. S. Tjeerdema

Copyright (C) 2011 M. Evren Ersahin et al. This is an open access article distributed under the Creative Commons Attribution License, which permits unrestricted use, distribution, and reproduction in any medium, provided the original work is properly cited.

\begin{abstract}
Energy recovery potential of a mesophilic co-digester treating OFMSW and primary sludge at an integrated biomethanization plant was investigated based on feasibility study results. Since landfilling is still the main solid waste disposal method in Turkey, land scarcity will become one of the most important obstacles. Restrictions for biodegradable waste disposal to sanitary landfills in EU Landfill Directive and uncontrolled long-term contamination with gas emissions and leachate necessitate alternative management strategies due to rapid increase in MSW production. Moreover, since energy contribution from renewable resources will be required more in the future with increasing oil prices and dwindling supplies of conventional energy sources, the significance of biogas as a renewable fuel has been increased in the last decade. Results indicated that almost $93 \%$ of annual total cost can be recovered if $100 \%$ renewable energy subsidy is implemented. Besides, considering the potential revenue when replacing transport fuels, about 26 heavy good vehicles or 549 cars may be powered per year by the biogas produced from the proposed biomethanization plant $\left(\mathrm{PE}=100,000 ; \mathrm{X}_{\mathrm{PS}}=61 \mathrm{~g} \mathrm{TS} / \mathrm{PE} \cdot\right.$ day; $\mathrm{X}_{\mathrm{SS}-\mathrm{OFMSW}}=50 \mathrm{~g} \mathrm{TS} / \mathrm{PE} \cdot$ day $)$.
\end{abstract}

\section{Introduction}

Primary energy sources are classified as fossil and renewable energy sources and nuclear fuels. Globally, most energy is provided from the fossil energy sources whereas nuclear power plants contribute to only a very small percentage. Therefore, the dependence of the global economy on fossilderived fuels, coupled with political instability in oil-producing countries, has pushed petroleum prices near all-time highs. On the other hand, although energy supply from renewable energy sources has been improved significantly, its contribution is quite limited. Water, sun, wind, geothermal heat, tides, and biomass are reported as the renewable energy sources. Since demand for energy is expected to increase more than $50 \%$ by 2025 , there is an ongoing search to develop sustainable, affordable, environmentally sound energy from renewable sources $[1,2]$. Biofuels derived from plant-based feedstocks, such as corn and sugarcane, are considered renewable and are an environmentally clean energy source, and they have potential to significantly decrease fossil fuel consumption. Bioethanol and biodiesel can be used in the form of a gasoline/diesel blend [2]. Besides, biogas which is produced at most biological treatment plants has been considered as one of the most important renewable energy sources. Anaerobic biotechnology has been reported as a sustainable alternative to current disposal strategies because the volume of the organic waste is reduced and stabilized, a residue (compost) that can be used for soil conditioning is produced, and energy in the form of methane is recovered [3]. Methane production can be estimated from chemical oxygen demand (COD) or ultimate biochemical oxygen demand $\left(\mathrm{BOD}_{\mathrm{L}}\right)$ stabilization based on the fact that $1 \mathrm{~kg}$ COD destroyed produces $0.35 \mathrm{~m}^{3} \mathrm{CH}_{4}$ at standard temperature and pressure (STP). Although methane 
generation is the focus, anaerobic biotechnology may also convert organic-rich waste streams into hydrogen or ethanol. Temperature, $\mathrm{pH}$, alkalinity, hydraulic and organic loading rates, the presence of toxic and inhibitory substances, type of substrate, and total solids (TS)/volatile solids (VS) content are the factors affecting the amount of gas produced. The methane content of biogas is also very important, because it imparts fuel value to the gas. It was reported that biogas, produced during anaerobic digestion of biodegradable organic solids, typically contains about $60-65 \%$ methane, which is a valuable resource and can be used to offset part of the energy needs for in-plant use. The produced biogas can replace natural gas, coal, and electricity. Moreover, the residues resulting from anaerobic digestion are rich in nutrients $(\mathrm{N}$ and $\mathrm{P}$ ) and can be land applied which also significantly reduce use of chemical fertilizer. In addition, the treated effluent can be recycled as process water for in-plant use $[2,4]$.

In the countries like Turkey where landfilling is still the main solid waste management method, land scarcity will become one of the most important obstacles for municipal solid wastes (MSW) disposal. It was reported that ca. $60 \times 10^{3}$ tonnes of MSW are produced per day in Turkey, which includes almost 50\% biodegradable materials. For instance in Istanbul, almost $45 \%$ of the produced MSW is in organic nature whereas $34 \%$ of it may be recovered and $21 \%$ is composed of miscellaneous materials. Thus, MSW should be considered as the "valuable products" instead of the "wastes" [5]. In the framework of the Kyoto agreements, which Turkey has already signed, the production of methane from wastes should be encouraged, for example, by subsidizing electricity from biogas with the net added price of as much as $€ 0.1$ per $\mathrm{kWh}$. Since current biomethane potential of the produced OFMSW in Turkey is about $10^{9} \mathrm{~m}^{3} \mathrm{CH}_{4}$ per year considering $50 \%$ biomethanization of $5 \times 10^{6}$ ton/year biodegradable waste as volatile solids (VSs), the biomethanization of OFMSW can become a feasible option by applying subsidies to electricity production from wastes [6]. In year 2000, the law of "Renewable Energies," which stated the rules for the subsidization of the power supplied by biogas facilities, became effective in Europe [1]. It was reported that around the world, the potential for biogas production is so large that it could replace about $20-30 \%$ of total natural gas consumption [4]. Moreover, the restrictions for biodegradable waste disposal in EU Landfill Directive [7] and uncontrolled long-term contamination with gas emissions and leachate necessitate alternative sustainable and integrated management strategies due to rapid increase in the production of MSW, that is, anaerobic biological treatment, either in anaerobic digesters or in landfill bioreactors $[8,9]$. It was reported that most wastes with a high-solid content, for example, municipal sludge (primary solids and waste-activated sludge (WAS)), animal manure, food wastes, and agricultural residues contain a significant amount of biodegradable organic carbon. These organicrich wastes and residues are ideal feedstocks for renewable energy (methane, hydrogen, or butanol) generation through nonoxidative metabolism (anaerobic fermentation) [10]. Codigestion of the organic fraction of municipal solid wastes (OFMSW) with other cosubstrates is reported as an attractive alternative for sustainable management of different separate waste streams produced at large amounts. Since codigestion concept involves the treatment of several types of waste in a single treatment facility, mixing of several waste types has positive effects both on the anaerobic digestion process itself and on the treatment economy which shows itself with an increase in methane yield and in process stability. The most appropriate cosubstrate alternatives for codigestion with OFMSW are reported as the sewage sludge which provides codigestion application to be realised in existing digesters at the treatment plants without great investments, a situation which makes this alternative more appealing. Moreover, theoretical $\mathrm{CH}_{4}$ content for primary sludge is reported as about $63 \%[3,4]$.

The aim of this study is to evaluate energy recovery potential if mesophilic $\left(30-35^{\circ} \mathrm{C}\right)$ codigestion of OFMSW with primary sludge is applied at a full-scale municipal wastewater treatment plant (WWTP) for 100,000 population equivalent (PE) (Figure 1). Here, the treatment plant is composed of an activated sludge system (C, N, and $\mathrm{P}$ removal) with presedimentation. The produced primary sludge will be codigested with the mixed wastes originating from the restaurants and canteens and from the supermarkets (greengrocery part) where both waste streams were the source sorted organic fraction of the municipal solid wastes (SS-OFMSWs). In the scope of this study, feasibility, biogas production and its potential revenue when replacing transport fuels (i.e., diesel or gasoline) were investigated for the proposed integrated biomethanization plant.

\section{The Mass Balance Calculations}

In order to calculate the fundamental data for the process design and to establish the mass balance, first of all the produced primary sludge and the OFMSW should be determined. The typical raw primary sludge production and its total solids (TSs) content from a municipal wastewater treatment plant are given in the ranges of $0.92-2.20 \mathrm{~L} / \mathrm{PE} \cdot$ day and $2-8 \%$, respectively [11]. If raw primary sludge production and its TS content are assumed as $1.5 \mathrm{~L} / \mathrm{PE}$-day and $4 \%$, respectively, primary sludge amount $\left(\mathrm{X}_{\mathrm{PS}}\right)$ is calculated as about $61 \mathrm{~g} / \mathrm{PE}$-day $\left(\right.$ density $\cong 1010 \mathrm{~kg} / \mathrm{m}^{3}$ ). TS content and VS/TS ratio for the SS-OFMSW from the restaurants and canteens are given in the range of $21.4-27.4 \%$ and $91-$ $99 \%$, respectively. On the other hand, TS content and VS/TS ratio for the SS-OFMSW from the greengrocery parts of the supermarkets are given in the range of $5.4-13.3 \%$ and $78-$ $92 \%$, respectively.

The OFMSW production from municipal sources is about $0.25 \mathrm{~kg} / \mathrm{PE}$-day. If the mixed SS-OFMSW production from the restaurants and canteens and from the greengrocery parts of the supermarkets is assumed as $20 \%$ of this amount, SS-OFMSW amount ( $\mathrm{X}_{\text {SS-OFMSW }}$ ) per capita is calculated as about $50 \mathrm{~g} / \mathrm{PE} \cdot$ day $(\mathrm{TS}=12 \%$; VS/TS $=90 \%$; density $\cong$ $1015 \mathrm{~kg} / \mathrm{m}^{3}$ ). If it is assumed that $20 \%$ of dual (separate) sorted (DS) OFMSW originating from households (only kitchen wastes) is added, XSS-OFMSW amount will increase to 


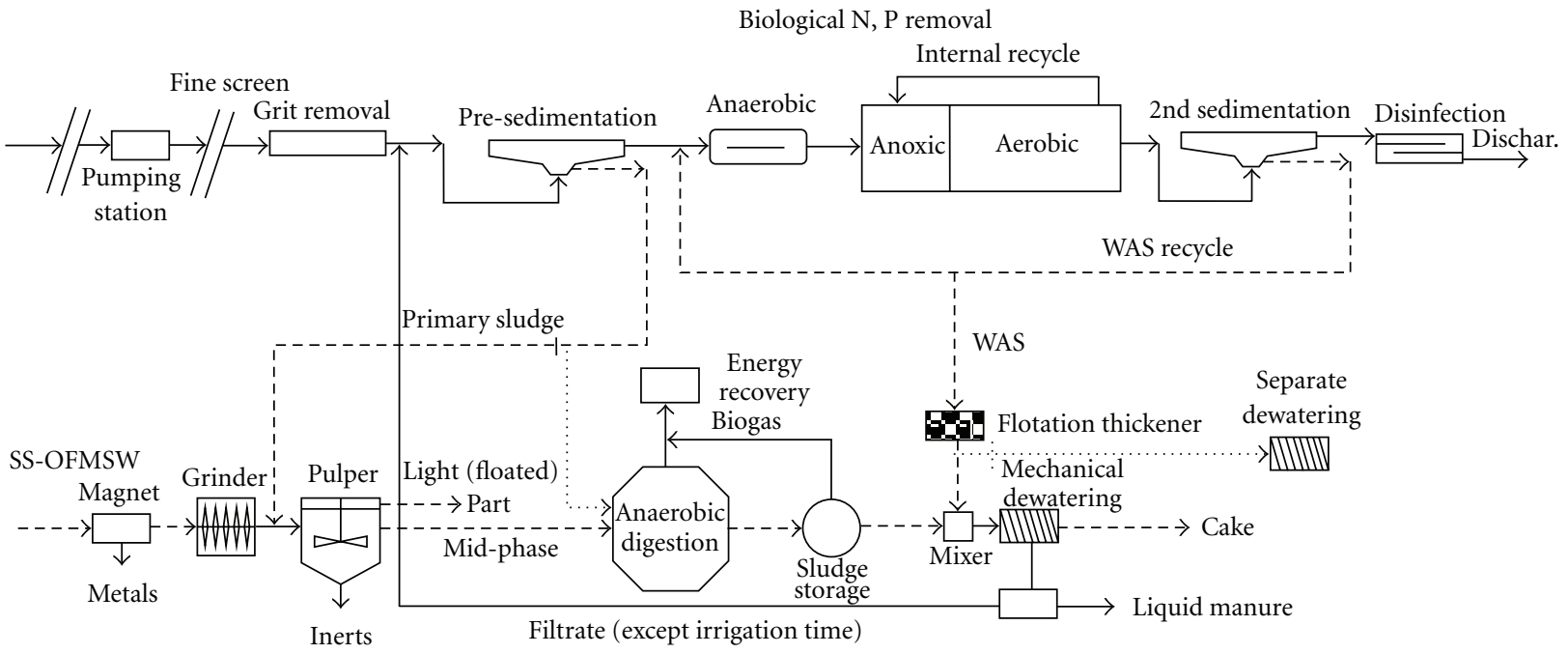

FIgURE 1: Process scheme of the municipal WWTP and the integrated biomethanization plant.

about $100 \mathrm{~g} / \mathrm{PE} \cdot$ day (i.e., $0.25 \times 0.2+0.05=0.1 \mathrm{~kg} / \mathrm{PE} \cdot$ day) . The amount of the $\mathrm{X}_{\text {SS-OFMSW would increase if DS-OFMSW }}$ addition is more than $20 \%$. In the light of the above given data, the flowrates of raw primary sludge and SSOFMSW as the influents of the pulper (Figure 1) can be calculated as about 150 and $41 \mathrm{~m}^{3}$ per day, respectively, for the $100,000 \mathrm{PE}$ plant. The effluent of the pulper is composed of the supernatant and the bottom phases which can be calculated as about 3 and $4 \mathrm{~m}^{3}$ per day, respectively. Therefore, the flowrate of the mid-phase (Figure 1) of the pulper (which is the influent of the anaerobic codigester when primary sludge is given to the effluent stream of the grinder) is about $184 \mathrm{~m}^{3} /$ day with a TS content of about $5.5 \%$. The results of the above calculations are summarized and explained in Table 1.

\section{Biomethane Recovery as a Potential Energy Source}

Since daily methane production is calculated as about $2220 \mathrm{~m}^{3}$ (Table 1), total annual savings based on electricity and heat energies can be determined as about $€ 263,350$ using (1) as follows:

$$
\begin{aligned}
\mathrm{M}_{\text {electricity }}= & 2220 \mathrm{~m}^{3} / \mathrm{d} \times 0.35 \times 10 \mathrm{kWh} / \mathrm{m}^{3} \mathrm{CH}_{4} \\
& \times € 0.07 / \mathrm{kWh} \times 365 \mathrm{~d} / \mathrm{yr} \approx € 198,525 / \text { year }, \\
\mathrm{M}_{\text {heat }}= & 2220 \mathrm{~m}^{3} / \mathrm{d} \times 0.40 \times 10 \mathrm{kWh} / \mathrm{m}^{3} \mathrm{CH}_{4} \\
& \times € 0.02 / \mathrm{kWh} \times 365 \mathrm{~d} / \mathrm{yr} \approx € 64,825 / \text { year. }
\end{aligned}
$$

However, since it is assumed that $85 \%$ of this energy can be sold in the market, net energy income is expected to be ca. $€ 223,850 / y r$. Here, energy potential per $\mathrm{m}^{3}$ of methane is approximately $33,810 \mathrm{~kJ}$ which corresponds to about $10 \mathrm{kWh}$. Unit energy selling prices are assumed according to Turkey's current market conditions, that is, €0.07 for electricity and $€ 0.02$ for heat per $\mathrm{kWh}$, respectively. If the above calculations are repeated according to $\mathrm{X}_{\mathrm{SS} \text {-OFMSW }}=$ $100 \mathrm{~g} / \mathrm{PE} \cdot$ day $\left(\mathrm{X}_{\mathrm{SS}-\mathrm{OFMSW}}=10 \mathrm{t} /\right.$ day for $\left.\mathrm{PE}=100,000\right)$, daily methane production is calculated as about $2980 \mathrm{~m}^{3}$ which corresponds to net energy income of about $€ 300,500$. Hence, results indicated that energy savings that can be recovered annually from the proposed biomethanization plant would be in the range of $€ 2.24-3.00$ per capita by the codigestion of the primary sludge and SS-OFMSW. This range may increase to $€ 4.48-6.00 / \mathrm{PE}$-year if $100 \%$ renewable energy subsidy is implemented. It was observed that over the past few years, the number of biogas facilities has been continuously rising in Europe, especially after implementing even higher subsidies. For example, in Germany about 1500 biogas facilities were in use. From these 1500 installed facilities, about $720 \mathrm{MW}$ electric power production is reported [1].

\section{Total Cost of the Biomethanization Plant}

Pretreatment of the feedstock is generally essential to enhance their digestibility and bioenergy generation potential because it was reported that one major challenge to the feedstocks is their slow digestibility and the rate-limiting hydrolysis step. In order to accelerate digestion, various pretreatment methods are applied such as mechanical, thermal, chemical, or biological which help solubilize particulate matter. Pretreatment would become a standard practice for all high-solids organic wastes and residues in the coming years [10]. In the scope of this study, a preliminary treatment unit (PTU) is included for the pretreatment of the SSOFMSW before the mesophilic anaerobic codigester. This unit consists of a magnet by which the metals are separated, a grinder, and a pulper. The primary sludge is not subjected to magnet and grinder but may be given to the effluent stream of the grinder when needed. In order to calculate total project cost including investment and operation and maintenance $(\mathrm{O} \& \mathrm{M})$ costs for the proposed integrated biomethanization plant, the cost for PTU (magnet, grinder, and pulper) 
TABLE 1: Summary of the mass balance for the proposed integrated biomethanization plant $\left(\mathrm{PE}=100,000 ; \mathrm{X}_{\mathrm{PS}}=61 \mathrm{~g} \mathrm{TS} / \mathrm{PE} \cdot \mathrm{day} ; \mathrm{X}_{\mathrm{SS}-\mathrm{OFMSW}}\right)$ $=50 \mathrm{~g} \mathrm{TS} / \mathrm{PE} \cdot$ day) (values in brackets show the case for $\mathrm{X}_{\mathrm{SS}-\mathrm{OFMSW}}=100 \mathrm{gr} / \mathrm{PE} \cdot$ day).

\begin{tabular}{|c|c|c|c|c|c|}
\hline Waste streams & TS (\%) & VS/TS (\%) & Density $\left(\mathrm{kg} / \mathrm{m}^{3}\right)$ & Total solids (t/day) & Flowrate $\left(\mathrm{m}^{3} /\right.$ day $)$ \\
\hline \multicolumn{6}{|c|}{ Pulper } \\
\hline Inlet (PS) & 4.0 & 80 & 1010 & 6 & $150(150)$ \\
\hline Inlet (SS-OFMSW) & $12(15)$ & $90(85)$ & $1015-1020$ & $5(10)$ & $41(66)$ \\
\hline Supernatant phase & 15 & - & 1015 & $\sim 0.50(\sim 1.0)$ & $3^{(1)}(5.5)$ \\
\hline Bottom phase & 12 & - & 1010 & $\sim 0.50(\sim 1.0)$ & $4^{(2)}(8)$ \\
\hline Outlet (PS+SS-OFMSW) & $5.5^{(3)}(7)$ & $90(85)$ & - & $10^{(4)}(14.2)$ & $184^{(5)}(202.5)$ \\
\hline \multicolumn{6}{|c|}{ Codigester } \\
\hline Inlet (PS + SS-OFMSW) & $5.5^{(3)}(7)$ & $90(85)$ & - & $10^{(4)}(14.2)$ & $184^{(5)}(202.5)$ \\
\hline Inert solids & - & $10(15)$ & - & $1.0(2.13)$ & - \\
\hline Excess sludge $\left(\mathrm{P}_{\mathrm{x}}\right)$ & - & - & - & $0.34^{(6,7)}(0.45)$ & - \\
\hline Outlet (digested sludge) & - & $83^{(8)}(75)$ & - & $5.84^{(8)}(8.615) 4.84^{(7,8)}(6.485)$ & - \\
\hline Solids converted into $\mathrm{CH}_{4}$ & - & - & - & $4.16^{(7,9)}(5.585)$ & $\sim 2220^{(10)}(\sim 2980)$ \\
\hline \multicolumn{6}{|c|}{$\begin{array}{l}\text { (1) If } 10 \% \text { of VS of OFMSW is wasted from the pulper with supernatant, then } 0.10 \times\left[\left(41 \times 10^{3} \times 0.12 \times 0.90\right) /(0.15 \times 1015)\right]=3 \text {. } \\
\text { (2) If } 10 \% \text { of inorganic materials in OFMSW is wasted from the bottom of the pulper, then } 0.10 \times\left[\left(41 \times 10^{3} \times 0.12\right) /(0.12 \times 1010)\right]=4 \text {. } \\
\text { (3) } 0.055=[(150 \times 0.04+41 \times 0.12)-(3 \times 0.15+4 \times 0.12) / 184] . \\
\text { (4) } 10=(184 \times 0.055) \\
\text { (5) } 184=[150+41-(3+4)] . \\
\text { (6) } \text { If VS/TS }=90 \%,=0.05 \text {, VS Removal } \mathrm{Y}_{\mathrm{obs}}=50 \% \text {, and } 1 \mathrm{~g} \mathrm{VS}=1.5 \mathrm{~g} \text { COD, then } \mathrm{P}_{\mathrm{x}}=[(10 \times 0.90) \times 0.50 \times 1.5 \times 0.05]=0.34 \text {. } \\
\text { (7) } \mathrm{As} \mathrm{volatile} \mathrm{solids.} \\
\text { (8) } 5.84=[(10 \times 0.10)+9 \times(1-0.50)+0.34] ; 4.84=(9 \times 0.50+0.34) ; 4.84 / 5.84=0.83\end{array}$} \\
\hline
\end{tabular}

should be determined. For this purpose, primary components of the investment cost which were already determined for a biomethanization plant treating OFMSW and the primary sludge for a $\mathrm{PE}=200,000$ capacity were taken into consideration [12]. According to the study, the primary investment cost components were construction including preconstruction (engineering and consultancy) and civil works as $\sim € 2.5 \times 10^{6}$, equipment (mechanical, electrical, instrumentation, piping, and mounting) as $\sim € 1.65 \times 10^{6}$, and thus giving a total investment cost of about $€ 4.15 \times 10^{6}$. On the other hand, annual O\&M cost without PTU was calculated ca. $€ 300,000 /$ year [12]. If investment cost for PTU is assumed as 25\% of total investment cost (for PE $=200,000$ plant) and if it is assumed that O\&M cost (for PE $=200,000$ plant) would increase by $20 \%$ by the addition of PTU, annual total cost is calculated as $€ 4.82 / \mathrm{PE}$-yr for the proposed biomethanization plant $(\mathrm{PE}=100,000)$. Cost estimation results are summarized in Table 2 , and change in annual cost values for the plants serving 100,000-1,000,000 PE is presented in Figure 2. Consequently, when compared with the annual energy savings (€4.48/PE·yr), almost $93 \%$ of annual total cost $(€ 4.82 / \mathrm{PE} \cdot$ year $)$ can be recovered from the proposed integrated biomethanization plant (for $\mathrm{PE}=$ 100,$000 ; X_{P S}=61 \mathrm{~g} / \mathrm{PE} \cdot$ day; $\mathrm{X}_{\mathrm{SS}-\mathrm{OFMSW}}=50 \mathrm{~g} / \mathrm{PE} \cdot$ day $)$ in the case of implementing $100 \%$ renewable energy subsidy with a payback period of 13.2 years.

Unfortunately, integrated biomethanization plants would not be much feasible without public subsidy at the current situation. Subsidies have undeniable effect on the improvement of renewable energy production. It is considered that energy subsidies not only cover operating costs of companies but also encourage access to the modern energy sources and

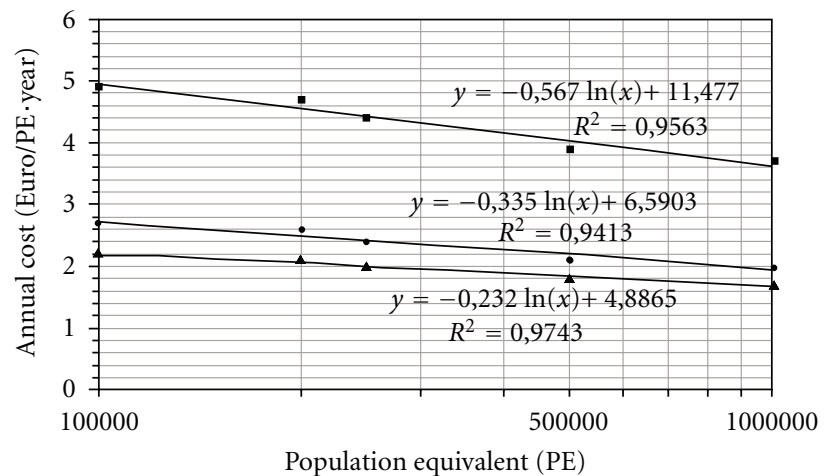

- Investment

- $\mathrm{O}$ and $\mathrm{M}$

- Total

FIGURE 2: Change in annual cost values for 100,000-1,000,000 PE.

help to reduce energy import dependency especially in developing countries such as Turkey. The gate fee (or tip-ping fee) for MSW disposal also has significant effect on the decrease of the payback period although no subsidy is implemented for energy. Municipalities currently pay approximately 15 Euro/tonne landfill gate fee for the MSW and municipal sludge in Turkey. However, this fee needs to be increased in order to meet EU limitations. Comparative costs of landfill in different EU Member States have indicated that gate fee values might fluctuate in the range of 6-220 Euro per tonne of waste excluding tax [13]. Regarding the proposed biomethanization plant, if approximately 40 Euro gate fee is assumed per tonne of waste, the payback period is calculated to be 3.2 years in the case of only gate fee implementation. 
TABLE 2: Summary of total cost estimated for the proposed biomethanization plant for 100,000 PE (adapted from Ozturk et al. [12]).

\begin{tabular}{lcc}
\hline Cost components & Unit & Value \\
\hline Construction works & $€\left(\times 10^{6}\right)$ & $1.78^{(1,2)}$ \\
Equipment & $€\left(\times 10^{6}\right)$ & $1.33^{(3,4)}$ \\
Total investment & $€\left(\times 10^{6}\right)$ & $3.11^{(5)}$ \\
Total investment & $€ / \mathrm{PE}$ & $31^{(6)}$ \\
Annual investment & $€ / \mathrm{yr}\left(\times 10^{6}\right)$ & $0.266^{(7)}$ \\
Annual investment & $€ / \mathrm{PE} \cdot \mathrm{yr}$ & $2.66^{(8)}$ \\
\hline \multicolumn{3}{c}{ O\&M } \\
\hline Annual O\&M & $€ / \mathrm{yr}\left(\times 10^{6}\right)$ & $0.216^{(9)}$ \\
Annual O\&M & $€ / \mathrm{PE} \cdot \mathrm{yr}$ & $2.16^{(10)}$ \\
\hline \multicolumn{3}{c}{ Total } \\
\hline Annual total & $€ / \mathrm{PE} \cdot \mathrm{yr}$ & $4.82^{(11)}$ \\
\hline
\end{tabular}

${ }^{(1)}$ If investment cost of PTU is $25 \%$ of total investment cost determined for $\mathrm{PE}=200,000$ and if $45 \%$ of total investment cost is assumed as the construction work, then $\left(2.5 \times 10^{6}+0.25 \times 4.15 \times 10^{6} \times 0.45\right)=2.97 \times 10^{6}$.

${ }^{(2)}$ Since the values were determined for $\mathrm{PE}=200,000$, and values were corrected for $\mathrm{PE}=100,000$ by $60 \%$, then $0.60 \times 2.97 \times 10^{6}=1.78 \times 10^{6}$.

${ }^{(3)}$ If investment cost of PTU is $25 \%$ of total investment cost determined for $\mathrm{PE}=200,000$ and if $55 \%$ of the total investment cost is assumed as the equipment work, then $\left(1.65 \times 10^{6}+0.25 \times 4.15 \times 10^{6} \times 0.55\right)=2.22 \times 10^{6}$.

${ }^{(4)}$ Since the values were determined for $\mathrm{PE}=200,000$, and values were corrected for $\mathrm{PE}=100,000$ by $60 \%$, then $0.60 \times 2.22 \times 10^{6}=1.33 \times 10^{6}$.

(5) $3.11 \times 10^{6}=(1.78+1.33) \times 10^{6}$.

${ }^{(6)}$ For $\mathrm{PE}=100,000,\left(3.11 \times 10^{6} \div 100000\right) \cong 31$.

(7) If interest + depreciation + amortization, lifetime, and CRF equal 6\%, 30 years, and 0.07265 for preconstruction and $6 \%, 15$ years, and 0.10296 for equipment works, then $1.78 \times 10^{6} \times 0.07265+1.33 \times 10^{6} \times 0.10296=0.266$. ${ }^{(8)}$ For $\mathrm{PE}=100,000,\left(0.266 \times 10^{6} \div 100000\right)=2.66$

${ }^{(9)} \mathrm{O} \& \mathrm{M}$ cost for $\mathrm{PE}=200,000$ would increase by $20 \%$ with PTU, and if values were corrected for $\mathrm{PE}=100,000$ by $60 \%$, then $[0.60 \times$ $(300,000 \times 1.2)]=216,000=0.216 \times 10^{6}$.

${ }^{(10)}$ For $\mathrm{PE}=100,000,\left(0.216 \times 10^{6} \div 100000\right)=2.16$

(11) $4.82=2.66+2.16$.

However, if public subsidy (as 100\%) is also implemented together with this gate fee, the payback period will shorten to 2.6 years indicating the positive effects of the incentives on system feasibility.

\section{Utilization of Biogas as Transport Fuel}

There are different ways of using the produced biogas from the biomethanization plants. These are (i) direct steam generation, (ii) direct combustion, for example, by internal combustion engines (ICE), (iii) simultaneous electricity and useful heat generation, that is, cogeneration at combined heat and power (CHP) plants, (iv) pumping into central natural gas grid after pretreatment, and (v) usage for powering vehicles after pretreatment. Typical fuel value is reported to be $22,400 \mathrm{~kJ}$ per $1 \mathrm{~m}^{3}$ normal biogas. Biogas can be used either for the production of heat only or for the generation of electric power. When current is obtained, normally heat is produced in parallel by the combined heat and power (CHP) generation plants. Here, biogas is converted to electricity using on-site power generation equipment at which heat is recovered in the form of hot water or steam for heating applications [1]. Although boilers and other direct combustion applications are by far the cheapest and easiest use options for energy utilization, CHP is one of the most common forms of energy recycling. Turkey has a wide-spread natural gas grid typically used as domestic and industrial power sources, and biogas generated from anaerobic digestion of wastes can also be distributed via this network for community use. However, it was reported that using biogas to power vehicles had the lowest carbon footprint, followed by the use of biogas on-site in a CHP plant. Pumping gas into the grid was the next most efficient [14]. Due to increased use of fossil fuels, atmospheric carbon dioxide which hastens the global warming crisis has also increased [2]. The EU Directive on the promotion of the use of energy from renewable sources sets ambitious targets for all Member States, such that the EU will reach a $20 \%$ share of energy from renewable sources by 2020 and a $10 \%$ share of renewable energy specifically in the transport sector [15]. Besides, key goals of the "An EU Strategy for Biofuels" is to promote the use of biofuel in transport with the aim of reducing the environmental impact of fossil fuels to define a minimum share of biofuel to be sold on the market of each Member State by 2010 [16]. Thus, use of biogas produced from the wastes as the fuel (gasoline and/or diesel) for transport has increased extensively in recent years. By this way, significant decreases in air emissions from the vehicles and noise pollution would be achieved, dependency on other countries to supply petroleum would cease, biogas wastage at the treatment plants via gas flares would be prevented, and a new income source as well as economic benefit would be provided. It was reported that biogas has been used as vehicle fuel in around 14 cities in Europe, among them the leading two countries are Sweden and Switzerland. For example, in Stockholm, the annual biogas production of about $1.5 \times 10^{6} \mathrm{~m}^{3}$ could power about 425 automobiles and 3 trucks, which was obtained from the municipal WWTP serving 600,000 PE $[4,17,18]$. However, some modifications are required on the vehicle and engine technologies. For example, gasoline and diesel vehicles need to be retrofitted for natural gas unless new vehicles are used. Biofuels need to be processed to consistent standards for optimal performance in ICE. Optimization of vehicles includes fine-tuning control systems and engine designs to run on varying blends for maximum fuel efficiency and minimum emissions across the full range of potential blend mixes. Since the Member States of EU must ensure that the minimum share of biofuels sold on their markets is $2 \%$ by 31 December 2005 at the latest, and $5.75 \%$ by December 2010, most of the automobile industries guarantee its usage safely $[16,19]$. Biogas should also comply some quality standards in order to be used as the fuel for transport purposes. Not only does biogas consist mainly of methane and $\mathrm{CO}_{2}$, but it also contains several impurities [1]. It was reported that biogas has to be upgraded to natural gas quality for use in vehicles designed to function on natural gas. This calls for removal of particulates, carbon dioxide, hydrogen sulfide, moisture, and any other contaminants present in the gas to increase the methane content to over $95 \%$ (by volume). The 
TABLE 3: Transport fuel substitutes of the produced biomethane $\left(\mathrm{PE}=100,000 ; \mathrm{X}_{\mathrm{PS}}=61 \mathrm{~g} \mathrm{TS} / \mathrm{PE} \cdot\right.$ day; $\left.\left.\mathrm{X}_{\mathrm{SS}-\mathrm{OFMSW}}\right)=50 \mathrm{~g} \mathrm{TS} / \mathrm{PE} \cdot \mathrm{day}\right)($ adapted from Murphy et al. [21]).

\begin{tabular}{|c|c|c|}
\hline Statement & Value & Unit \\
\hline \multicolumn{3}{|c|}{ Replacement of diesel in heavy good vehicles (operating at $6 \mathrm{mpg}$ on diesel $0.052 \mathrm{~km} / \mathrm{MJ}$ ) } \\
\hline Heavy good vehicle operating on $\mathrm{CH}_{4}$-enriched biogas, $90 \%$ efficiency of diesel & 0.047 & $\mathrm{~km} / \mathrm{MJ}$ \\
\hline $\begin{array}{l}\text { Potential travel distance powered by biogas: }\left(2340 \mathrm{~m}^{3} / \text { day } \times 330^{(1)} \text { day } / \text { year } \times 35.9^{(2)}\right. \\
\left.\mathrm{MJ} / \mathrm{m}^{3} \times 0,047 \mathrm{~km} / \mathrm{MJ}\right)\end{array}$ & $1,302,933$ & $\mathrm{~km} / \mathrm{yr}$ \\
\hline Number of heavy good vehicles powered (50,000 km per year) & 26 & - \\
\hline Diesel substituted of $1 \mathrm{~m}^{3}$ enriched biogas: $[2340 \times 330 \times 35.9 \times(0.047 / 0.052)] \div\left(40.7^{(3,4)}\right)$ & $615,636(\sim 0.8)^{(5)}$ & $\mathrm{L} / \mathrm{yr}\left(\mathrm{L} / \mathrm{m}^{3}\right)$ \\
\hline \multicolumn{3}{|c|}{ Replacement of gasoline in cars (operating at $40 \mathrm{mpg}$ on gasoline $0.439 \mathrm{~km} / \mathrm{MJ}$ ) } \\
\hline Car operating on $\mathrm{CH}_{4}$-enriched biogas, $90 \%$ efficiency of gasoline & 0.396 & $\mathrm{~km} / \mathrm{MJ}$ \\
\hline $\begin{array}{l}\text { Potential travel distance powered by biogas: }\left(2340 \mathrm{~m}^{3} / \text { day } \times 330^{(1)} \text { day } / \text { year } \times 35.9^{(2)}\right. \\
\left.\mathrm{MJ} / \mathrm{m}^{3} \times 0.396 \mathrm{~km} / \mathrm{MJ}\right)\end{array}$ & $10,977,904$ & $\mathrm{~km} / \mathrm{yr}$ \\
\hline Number of cars powered $(20,000 \mathrm{~km}$ per year $)$ & 549 & - \\
\hline $\begin{array}{l}\text { Gasoline substituted of } 1 \mathrm{~m}^{3} \text { enriched biogas: }[2340 \times 330 \times 35.9 \times(0.396 / 0.439)] \div \\
\left(32.23^{(3,4)}\right)\end{array}$ & $775,880(\sim 1.0)^{(5)}$ & $\mathrm{L} / \mathrm{yr}\left(\mathrm{L} / \mathrm{m}^{3}\right)$ \\
\hline \multicolumn{3}{|c|}{$\begin{array}{l}{ }^{(1)} \text { Annual operation period of } 330 \text { days is assumed. } \\
{ }^{(2)} \text { Energy value of } 1 \mathrm{~m}^{3} \text { enriched biogas }\left(95 \% \mathrm{CH}_{4}\right) \text { is } 35.9 \mathrm{MJ} \text {. } \\
\text { (3) Energy value of oil } 47.89 \mathrm{GJ} / \mathrm{T} \text {; densities of diesel and gasoline are } 850 \text { and } 673 \mathrm{~kg} / \mathrm{m}^{3} \text {, respectively. } \\
{ }^{(4)} \text { Energy values of diesel and gasoline are } 40.7 \mathrm{MJ} / \mathrm{L}(47.89 \times 0.850) \text { and } 32.23 \mathrm{MJ} / \mathrm{L}(47.89 \times 0.673) \text {, respectively. } \\
{ }^{(5)} \text { Since annual } \mathrm{CH}_{4} \text {-enriched biogas production is } 2340 \mathrm{~m}^{3} / \mathrm{d} \times 330 \mathrm{~d} / \mathrm{yr} \cong 772,200 \mathrm{~m}^{3} / \mathrm{yr},(615,636 \div 772,200) \cong 0.8 \mathrm{~L} / \mathrm{m}^{3} \text { for diesel and }(775,880 \div 772,200) \\
\cong 1.0 \mathrm{~L} / \mathrm{m}^{3} \text { for gasoline. }\end{array}$} \\
\hline
\end{tabular}

carbon dioxide present in biogas dilutes the fuel value of the gas and has to be removed. Hydrogen sulfide can increase corrosion in the presence of water and moisture can cause clogging at lower temperatures. For this purpose, the biogas should be purified by a suitable method, for example, by water scrubbing. [4]. Then this purified biogas can be stored under 200-250 bar pressure at biogas stations and can be sold afterwards. Since clean biogas has the same characteristics as natural gas, the existing natural gas infrastructure can support the use of biogas. Generally biogas is mixed with natural gas, and blending with natural gas can also enhance the distribution of biogas even at relatively small quantities. Moreover, $\mathrm{CO}_{2}, \mathrm{NO}_{\mathrm{x}}$, and particulate emissions are reported at much lower rates compared to other fuel types; for example, $\mathrm{CO}$, hydrocarbon, $\mathrm{NO}_{\mathrm{x}}, \mathrm{CO}_{2}$, and particulate emissions from heavy good vehicles powered by biogas are almost 2.5-, 1.14-, 0.6-, 5-, and 7-folds lower than the heavy good vehicles powered by diesel, respectively. It is also reported that benzene (which is a known human carcinogen) emissions are eliminated [4]. Tilche and Galatola [20] reported that the use of biomethane, in particular as biofuel, has been shown to be able to produce large greenhouse gas savings. Methane amounts for the proposed integrated biomethanization plant (at $35^{\circ} \mathrm{C}$ and $1 \mathrm{~atm}$ ) were calculated as $2220 \mathrm{~m}^{3} /$ day $\left(\mathrm{X}_{\mathrm{SS}-\mathrm{OFMSW}}=50 \mathrm{~g} \mathrm{TS} / \mathrm{PE} \cdot\right.$ day $)$ and $2980 \mathrm{~m}^{3} /$ day $\left(\mathrm{X}_{\text {SS-OFMSW }}=100 \mathrm{~g} \mathrm{TS} / \mathrm{PE} \cdot\right.$ day $) . \mathrm{CH}_{4}$-enriched biogas $(95 \%$ $\mathrm{CH}_{4}$ ) equivalents of the above values can be calculated as 2340 and $3140 \mathrm{~m}^{3} /$ day, respectively. Since $1 \mathrm{~m}^{3}$ enriched biogas replaces about $0.8 \mathrm{~L}$ of diesel or $1.0 \mathrm{~L}$ of gasoline according to Table 3, annual amounts in diesel or gasoline substitutes are about 615,636 or $775,880 \mathrm{~L}$, respectively, for $2340 \mathrm{~m}^{3} /$ day $\mathrm{CH}_{4}$-enriched biogas. Moreover, results showed that about 26 or $549\left(\mathrm{X}_{\mathrm{SS}-\mathrm{OFMSW}}=50 \mathrm{~g} \mathrm{TS} / \mathrm{PE} \cdot\right.$ day $)$ and 35 or $737\left(\mathrm{X}_{\mathrm{SS}-\mathrm{OFMSW}}=100 \mathrm{~g} \mathrm{TS} / \mathrm{PE} \cdot\right.$ day $)$ heavy good vehicles and cars could be powered by the produced biogas from the proposed integrated biomethanization plant $(\mathrm{PE}=100,000)$ instead of diesel or gasoline, respectively. The production cost and the selling price of $1 \mathrm{~m}^{3}$ biogas are reported in the ranges of $€ 0.2-0.75$ and $€ 0.66-1.1$, respectively [17]. Transport fuel susbstituted values determined for the proposed biomethanization plant are summarized in Table 3.

\section{Conclusion}

The significance of renewable alternative fuels has increased in the last decade due to dwindling supplies of conventional energy sources and rising oil prices. Since natural gas and electricity costs have been increasing day by day, the share of renewable energy in total global energy consumption increases and energy recovery from biogas becomes attractive. Biogas is reported as one of the most important renewable energy sources, and biogas production is mainly based on anaerobic digestion of organic wastes. Turkey's oil import bills likely to grow and put increasing pressure on the economy. Turkey has the highest gasoline and diesel prices in the world, and there is a high motivation and public acceptance in alternative and relatively cheaper fuels. Only about $0.2 \%$ of current energy power in Turkey is obtained from biogas and solid wastes. Since the current energy production is heavily dependant on the imported natural gas and coal in Turkey, renewable energy recovery by anaerobic digestion of organic wastes (biomethanization) has been gaining vital importance in recent years. Towards the EU membership of Turkey, waste minimization and recovery strategy will be based on this approach especially in metropolitan cities. Codigestion of OFMSW with other cosubstrates is reported as an attractive alternative for sustainable management of 
different separate waste streams produced at large amounts. Although, the most appropriate cosubstrate alternatives for codigestion with OFMSW are reported as the sewage sludge, animal slurries, garden wastes, fruit wastes, and so forth, they may be also used as alternative feedstocks. In this study, an integrated biomethanization plant is proposed at which primary sludge is codigested with SS-OFMSW (mixed wastes originating from the restaurants and canteens and from the greengrocery parts of the supermarkets). Results of this study indicated that almost $93 \%$ of annual total cost can be recovered if $100 \%$ renewable energy subsidy is implemented with a payback period of 13.2 years. However, if approximately 40 Euro gate fee is also implemented per tonne of waste with public subsidy, the payback period would shorten to 2.6 years indicating the positive effects of the incentives on system feasibility. Since landfilling is still the main solid waste disposal method in Turkey, other benefits of the proposed biomethanization plant would be the reduction of landfill volume requirement and the protection of the groundwater.

In accordance with the EU, the authoritatives in Turkey are aware of that serious precautions should be taken in terms of sustainable environmental protection such as usage of alternative fuels for transport. For example, urban air pollution is often a key driver of alternative fuels for transport in developing countries due to its magnitude and visibility and the degree of public exposure to the problem. In this scope, if transport fuel substitute of the produced biogas is calculated, about 26 heavy good vehicles using diesel or 549 cars using gasoline may be powered per year ( $\mathrm{PE}=$ 100,$000 ; \mathrm{X}_{\mathrm{PS}}=61 \mathrm{~g}$ TS/PE$\cdot$ day; $\mathrm{X}_{\text {SS-OFMSW }}=50 \mathrm{~g}$ TS/PE$\cdot$ day). The number of heavy good vehicles or cars might increase up to 35 or 737 in the case of $\mathrm{X}_{\text {SS-OFMSW }}=100 \mathrm{~g} \mathrm{TS} / \mathrm{PE} \cdot$ day. However, the biogas has to be upgraded for use in vehicles, and some modifications are required on the vehicle and engine technologies.

It is known for certain that number of such proposed biogas plants will increase in Turkey following the government incentive to promote their installations. However, the related regulations regarding energy productivity, environment, Kyoto agreements, clean ecoproduction, and renewable energy should be immediately completed with the supply of the required infrastructure for investment.

\section{Acknowledgment}

The authors gratefully acknowledge The Scientific and Technological Research Council of Turkey (TUBITAK) (Project no. 105G024) for the financial support.

\section{References}

[1] D. Deublein and A. Steinhauser, Biogas from Waste and Renewable Resources: An Introduction, Wiley-VCH, Weinheim, Germany, 2008.

[2] S. K. Khanal, "Bioenergy generation from residues of biofuel industries," in Anaerobic Biotechnology for Bioenergy Production: Principles and Applications, S. K. Khanal, Ed., pp. 161-188, Wiley-Blackwell, Oxford, UK; John Wiley \& Sons, New York, NY, USA, 2008.

[3] H. Hartmann, I. Angelidaki, and B. K. Ahring, "Co-digestion of the organic fraction of municipal waste with other waste types," in Biomethanization of the Organic Fraction of Municipal Solid Wastes, J. Mata-Alvarez, Ed., pp. 181-199, IWA, London, UK, 2002.

[4] S. Harikishan, "Biogas processing and utilization as an energy source," in Anaerobic Biotechnology for Bioenergy Production: Principles and Applications, S. K. Khanal, Ed., pp. 267-291, Wiley-Blackwell, Oxford, UK; John Wiley \& Sons, New York, NY, USA, 2008.

[5] I. Ozturk, A. Bir, A. F. Aydin et al., "Investigation of bioenergy recovery technologies (biomethanisation) by integrated treatment of municipal wastewaters and organic fraction of solid wastes," Final Report 105G024, The Scientific and Technical Research Council of Turkey (TUBITAK), 2009.

[6] R. K. Dereli, M. E. Ersahin, C. Y. Gomec, I. Ozturk, and O. Ozdemir, "Co-digestion of the organic fraction of municipal solid waste with primary sludge at a municipal wastewater treatment plant in Turkey," Waste Management and Research, vol. 28, no. 5, pp. 404-410, 2010.

[7] EU Council Directive, EU Council Directive on the Landfill of Waste, 99/31/EC, 1999.

[8] M. Balat and H. Balat, "Biogas as a renewable energy sourcea review," Energy Sources A, vol. 31, no. 14, pp. 1280-1293, 2009.

[9] F. G. Pohland, A. B. Al-Yousfi, and D. R. Reinhard, "Anaerobic digestion of organic solid waste in bioreactor landfills," in Biomethanization of the Organic Fraction of Municipal Solid Wastes, J. Mata-Alvarez, Ed., pp. 303-315, IWA, London, UK, 2002.

[10] S. Harikishan, "Pretreatment of high-solids wastes/residues to enhance bioenergy recovery," in Anaerobic Biotechnology for Bioenergy Production: Principles and Applications, S. K. Khanal, Ed., pp. 247-265, Wiley-Blackwell, Oxford, UK; John Wiley \& Sons, New York, NY, USA, 2008.

[11] L. Spinosa and P. A. Vesilind, Sludge into Biosolids Processing, Disposal, Utilization, IWA, London, UK, 2001.

[12] I. Ozturk, R. K. Dereli, A. Ozabali, K. Ericyel, and I. Karakaya, "The feasibility report of Central Biomethanization Plant of Stock Farmer Union in Suluova (Amasya) at the Stock Organised Industrial District,” Istanbul, 2009.

[13] D. Hogg, "Costs for municipal waste management in the EU," Final Report, Directorate General Environment, European Commission, Eunomia Research \& Consulting, Bristol, UK, 2001.

[14] Letsrecycle.com, "Research raises questions over best use of biogas," London, UK, 2010, http://www.letsrecycle.com/do/ ecco.py/view_item?listid=37\&listcatid $=5477 \&$ listitemid $=5634$ \&section=composting.

[15] EU Council Directive, Directive 2009/28/EC of The European Parliament and of The Council of 23 April 2009 on the promotion of the use of energy from renewable sources and amending and subsequently repealing Directives 2001/77/EC and 2003/30/EC, 2009/28/EC, 2009.

[16] An EU Strategy for Biofuels \{SEC(2006)142\}, COM(2006) 34 final, 2006.

[17] G. Landahl and C. Plombin, "Trendsetter: biogas in European vehicles," in Resource Recovery and Reuse in Organic Solid Waste Management, P. Lens and B. Hamelers, Eds., pp. 411422, IWA, London, UK, 2004.

[18] G. Boyle, "An overview of alternative transport fuels in developing countries: drivers, status, and factors influencing 
market deployment," in Hydrogen Fuel Cells and Alternatives in the Transport Sector: Issues for Developing Countries, United Nations University International Conference, November 2005.

[19] "Biofuels for Transportation Global Potential and Implications for Sustainable Agriculture and Energy in the 21st Century," Worldwatch Institute, Washington, DC, USA, 2006, http://www.worldwatch.org/system/files/EBF038.pdf.

[20] A. Tilche and M. Galatola, "The potential of bio-methane as bio-fuel/bio-energy for reducing greenhouse gas emissions: a qualitative assessment for Europe in a life cycle perspective," Water Science and Technology, vol. 57, no. 11, pp. 1683-1692, 2008.

[21] J. D. Murphy, E. McKeogh, and G. Kiely, "Technical/economic/environmental analysis of biogas utilisation," Applied Energy, vol. 77, no. 4, pp. 407-427, 2004. 

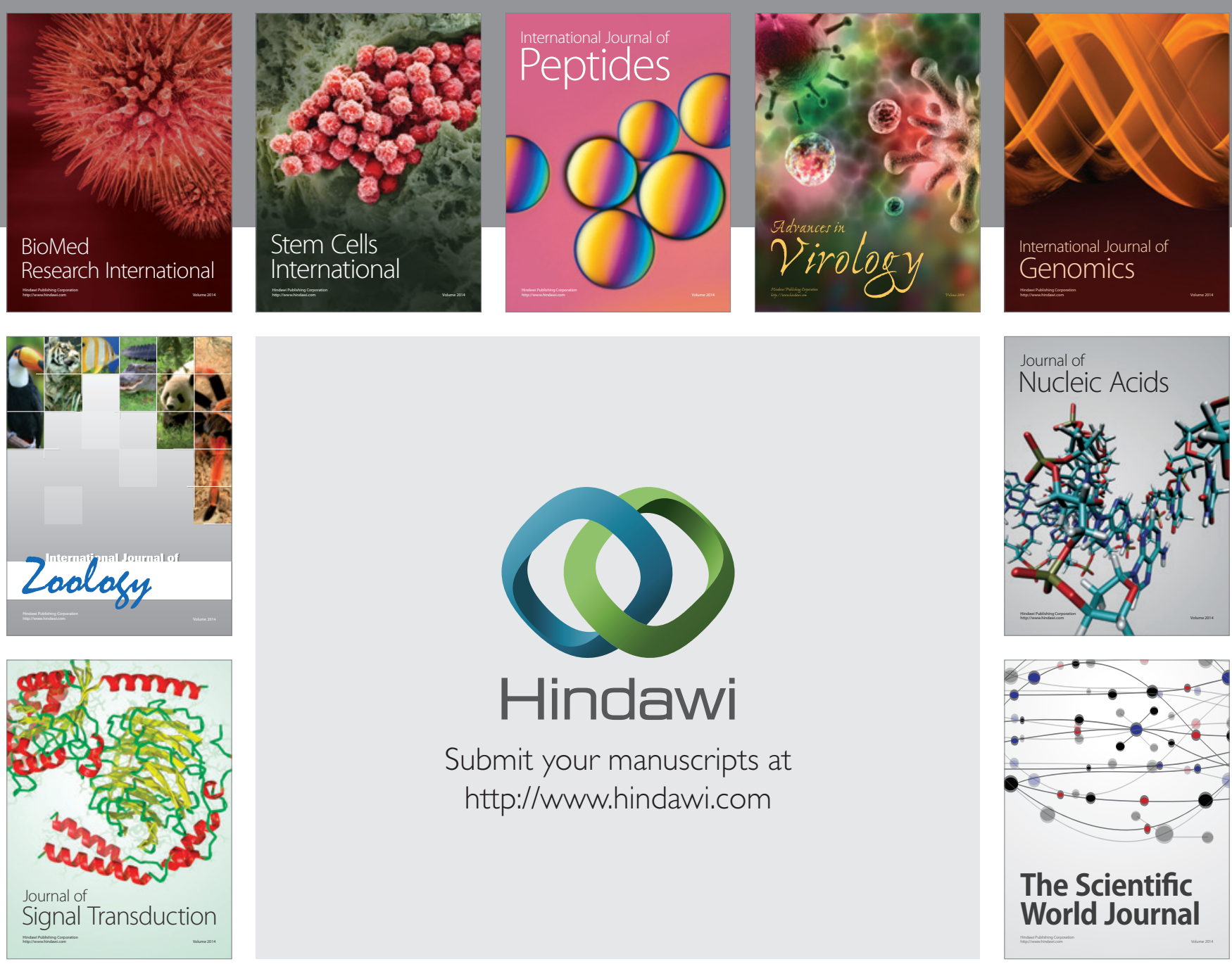

Submit your manuscripts at

http://www.hindawi.com
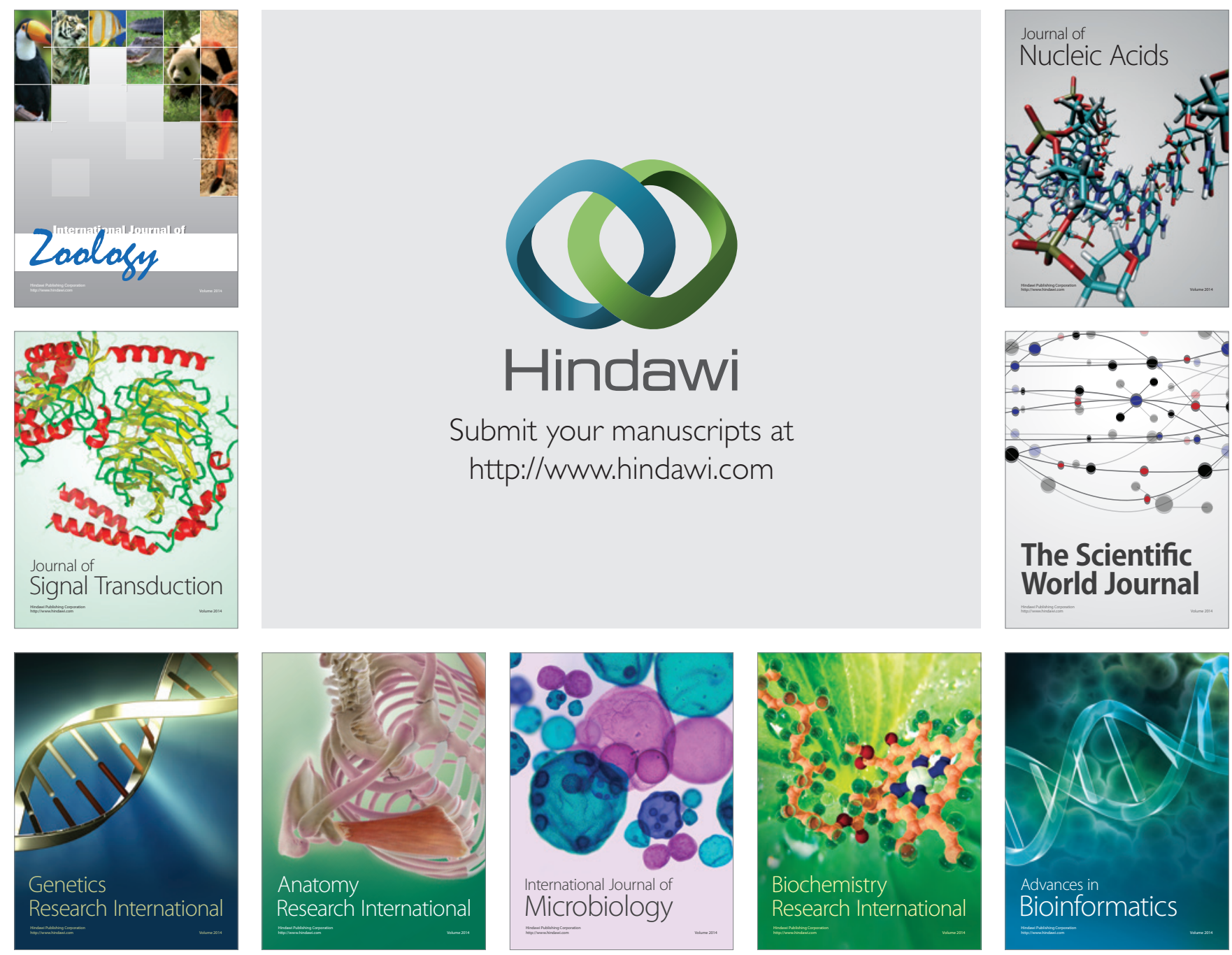

The Scientific World Journal
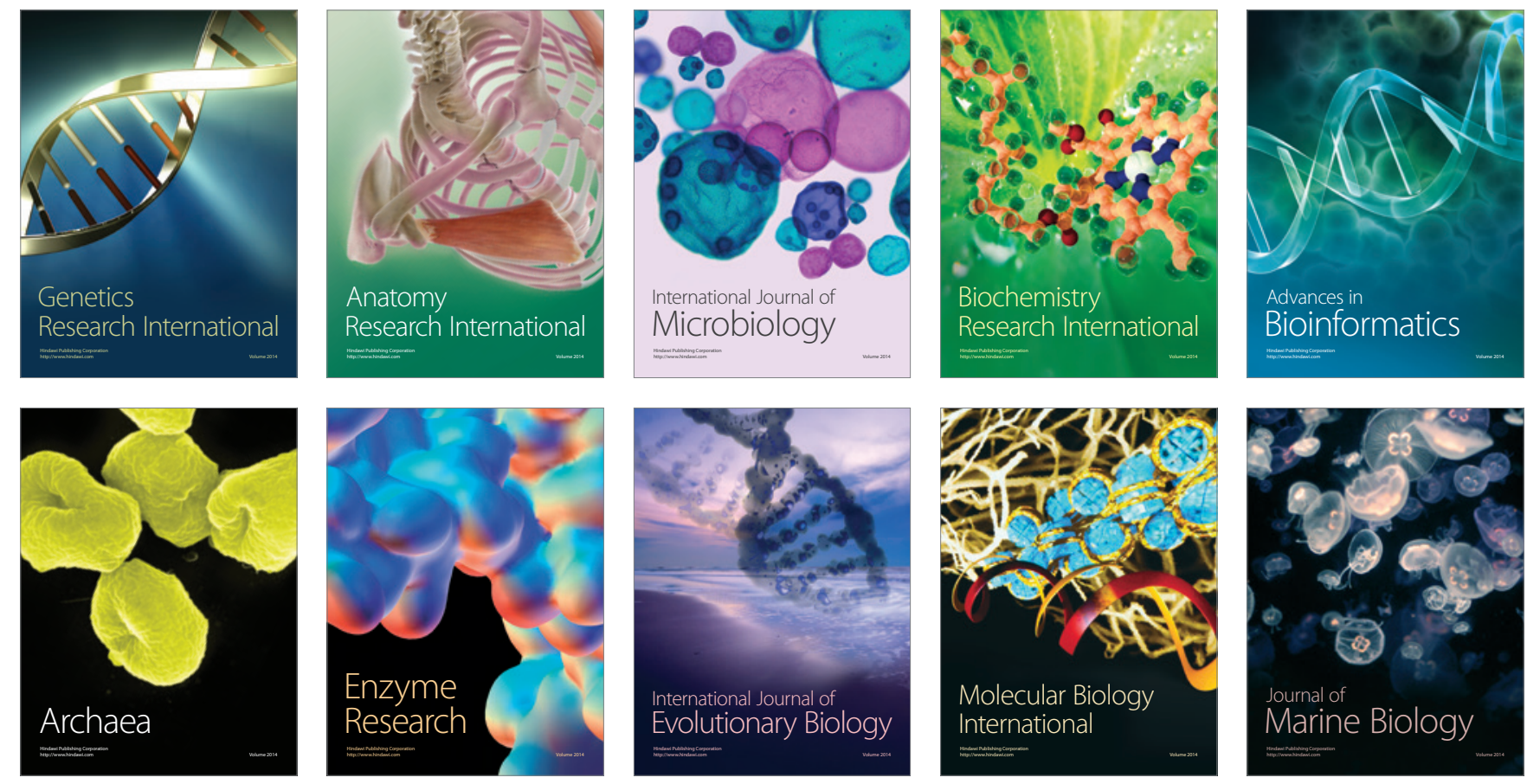